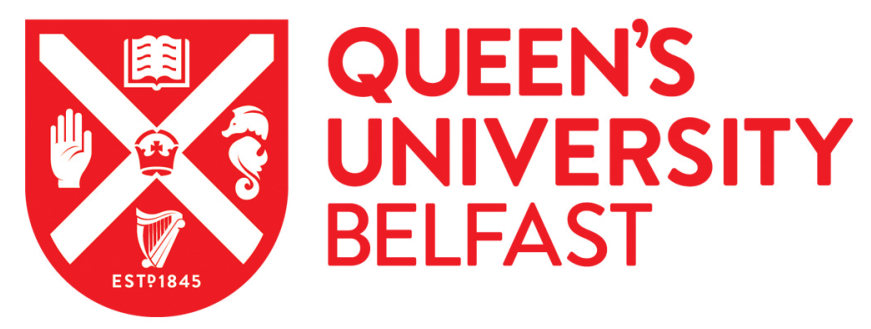

\title{
Analysis of Mitochondrial Transfer in Direct Co-cultures of Human Monocyte-derived Macrophages (MDM) and Mesenchymal Stem Cells (MSC)
}

Jackson, M. V., \& Krasnodembskaya, A. D. (2017). Analysis of Mitochondrial Transfer in Direct Co-cultures of Human Monocyte-derived Macrophages (MDM) and Mesenchymal Stem Cells (MSC). Bio-protocol, 7(9), [2255]. https://doi.org/10.21769/BioProtoc.2255

Published in:

Bio-protocol

Document Version:

Publisher's PDF, also known as Version of record

Queen's University Belfast - Research Portal:

Link to publication record in Queen's University Belfast Research Portal

Publisher rights

(c) 2017 The Authors.

This work is made available online in accordance with the publisher's policies. Please refer to any applicable terms of use of the publisher.

\section{General rights}

Copyright for the publications made accessible via the Queen's University Belfast Research Portal is retained by the author(s) and / or other copyright owners and it is a condition of accessing these publications that users recognise and abide by the legal requirements associated with these rights.

Take down policy

The Research Portal is Queen's institutional repository that provides access to Queen's research output. Every effort has been made to ensure that content in the Research Portal does not infringe any person's rights, or applicable UK laws. If you discover content in the Research Portal that you believe breaches copyright or violates any law, please contact openaccess@qub.ac.uk. 


\title{
Analysis of Mitochondrial Transfer in Direct Co-cultures of Human Monocyte-derived Macrophages (MDM) and Mesenchymal Stem Cells (MSC) \\ Megan V. Jackson and Anna D. Krasnodembskaya*
}

\author{
Centre for Experimental Medicine, School of Medicine, Dentistry and Biomedical Sciences, Queen's \\ University Belfast, Belfast, Northern Ireland \\ *For Correspondence: a.krasnodembskaya@qub.ac.uk
}

\begin{abstract}
[Abstract] Mesenchymal stem/stromal cells (MSC) are adult stem cells which have been shown to improve survival, enhance bacterial clearance and alleviate inflammation in pre-clinical models of acute respiratory distress syndrome (ARDS) and sepsis. These diseases are characterised by uncontrolled inflammation often underpinned by bacterial infection. The mechanisms of MSC immunomodulatory effects are not fully understood yet. We sought to investigate MSC cell contact-dependent communication with alveolar macrophages (AM), professional phagocytes which play an important role in the lung inflammatory responses and anti-bacterial defence. With the use of a basic direct co-culture system, confocal microscopy and flow cytometry we visualised and effectively quantified MSC mitochondrial transfer to AM through tunnelling nanotubes (TNT). To model the human AM, primary monocytes were isolated from human donor blood and differentiated into macrophages (monocyte derived macrophages, MDM) in the presence of granulocyte macrophage colony-stimulating factor (GM-CSF), thus allowing adaptation of an AM-like phenotype (de Almeida et al., 2000; Guilliams et al., 2013). Human bone-marrow derived MSC, were labelled with mitochondria-specific fluorescent stain, washed extensively, seeded into the tissue culture plate with MDMs at the ratio of 1:20 (MSC/MDM) and co-cultured for $24 \mathrm{~h}$. TNT formation and mitochondrial transfer were visualised by confocal microscopy and semi-quantified by flow cytometry. By using the method we described here we established that MSC use TNTs as the means to transfer mitochondria to macrophages. Further studies demonstrated that mitochondrial transfer enhances macrophage oxidative phosphorylation and phagocytosis. When TNT formation was blocked by cytochalasin B, MSC effect on macrophage phagocytosis was completely abrogated. This is the first study to demonstrate TNT-mediated mitochondrial transfer from MSC to innate immune cells.
\end{abstract}

Keywords: Mesenchymal stem cells, Macrophages, Mitochondrial transfer, ARDS, Phagocytosis, Oxidative phosphorylation

[Background] Data from pre-clinical studies, including studies by our group (Xu et al., 2007 and 2008; Nemeth et al., 2009; Gupta et al., 2007 and 2012; Krasnodembskaya et al., 2010 and 2012; Mei et al., 2010; Lee et al., 2013; Jackson et al., 2016) demonstrated strong potential for MSC as a future cell-based therapy for the treatment of ARDS, an injurious hyper-inflammatory condition of the lung. In these studies MSC have displayed regenerative, immune-modulatory and anti-microbial effects which have consequently provided rationale for the design of phase I and phase II clinical trials for MSC in 
ARDS (Zheng et al., 2014; Wilson et al., 2015). However, despite the rapid translation of MSC into the clinical trials, mechanisms of how MSC alleviate symptoms of ARDS still need to be fully elucidated. Recent studies have reported MSC modulate lung epithelial and endothelial cells through mitochondrial transfer via TNTs, resulting in improvement of the host cell bioenergetics (Islam et al., 2012; Ahmad et al., 2014; Li et al., 2014; Liu et al., 2014). In ARDS, excessive pulmonary inflammation is one of the main characteristics of the disease in which alveolar macrophages (AM) are prominent cells. They orchestrate the inflammatory responses in the alveoli and play an important role in the lung bacterial clearance (Ware and Matthay, 2000; Jackson et al., 2016).

This protocol allowed us to study the functional effects of a TNT mediated process of an organelle transfer between MDMs both in vitro and using the same staining protocol, mouse alveolar macrophages in vivo (Jackson et al., 2016). Although the major focus of our study was mitochondrial transfer, this protocol can be adapted with slight modifications for investigations of transfer of other organelles or even fluorescently labelled molecules.

\section{Materials and Reagents}

A. Extraction of mononuclear cells from human donor Buffy Coats

1. $50 \mathrm{ml}$ Falcon tubes (SARSTEDT, catalog number: 62.554 .502 )

2. T175 culture flasks (Thermo Fisher Scientific, Thermo Scientific ${ }^{T M}$, catalog number: 178883)

3. Sterile Pasteur pipettes (BIOLOGIX GROUP LTD Technical, catalog number: 30-0138A1)

4. Cover slip

5. Tissue culture coated 6 well plate (Thermo Fisher Scientific, Thermo Scientific ${ }^{\mathrm{TM}}$, catalog numbers: 140675)

6. Buffy coats are obtained from the Northern Ireland Blood Transfusion Service (NIBTS) following ethical approval by the School Research Ethics Committee of Queen's University Belfast

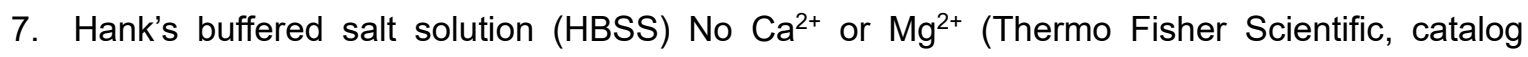
number: 14170138)

8. Ficoll-Paque (GE Healthcare, catalog number: 17-5442-03)

9. Complete RPMI 1640 (Thermo Fisher Scientific, Gibco ${ }^{\text {TM }}$, catalog number: 21875034)

10. Foetal calf serum (FCS) (heat inactivated) (Thermo Fisher Scientific, Gibco ${ }^{\mathrm{TM}}$, catalog number: 10270106)

11. Granulocyte-macrophage colony stimulating factor (GM-CSF) (PeproTech, catalog number: 300-03)

12. Penicillin/streptomycin $10,000 \mathrm{U} / \mathrm{ml}$ (Thermo Fisher Scientific, Gibco ${ }^{\mathrm{TM}}$, catalog number: 15140122)

13. Trypan blue (Thermo Fisher Scientific, Gibco ${ }^{\mathrm{TM}}$, catalog number: 15250061)

14. Complete 1\% FBS RPMI (see Recipes)

15. Complete RPMIGM-CSF (see Recipes) 
B. Culture of human bone marrow-derived mesenchymal stromal cells (MSC)

1. $50 \mathrm{ml}$ Falcon tubes (SARSTEDT, catalog number: 62.554.502)

2. 8-well chamber slides (Sigma-Aldrich, catalog number: C7182)

3. Tissue culture coated 6-well and 24-well plates (Thermo Fisher Scientific, Thermo Scientific ${ }^{\top M}$, catalog numbers: 140675,142475$)$

4. Pechiney PM999 Parafilm (Bemis, catalog number: PM999)

5. Microscope slide

6. Sterile Eppendorf tubes (SARSTEDT, catalog number: 72.690.001)

7. Flow tubes (SARSTEDT, catalog number: 55.475)

8. Human bone marrow-derived MSCs are obtained from the NIH repository in Texas A\&M Health Science Centre College of Medicine, Institute for Regenerative Medicine (Temple, Texas). The cells meet all the criteria for the classification as MSCs as defined by the International Society of Cellular Therapy (Dominici et al., 2006)

9. Liquid nitrogen

10. Dulbecco's phosphate buffered saline (DPBS) (Thermo Fisher Scientific, Gibco ${ }^{\mathrm{TM}}$, catalog number: 14190094)

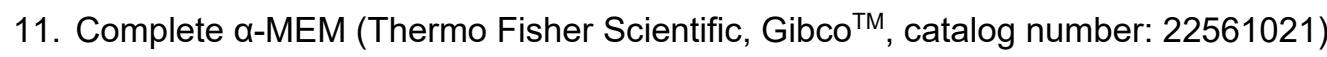

12. Penicillin/streptomycin $10,000 \mathrm{U} / \mathrm{ml}$ (Thermo Fisher Scientific, Gibco ${ }^{\mathrm{TM}}$, catalog number: 15140122)

13. L-glutamine (Thermo Fisher Scientific, Gibco ${ }^{T M}$, catalog number: 25030024)

14. Cytochalasin B (Sigma-Aldrich, catalog number: C6762)

15. 10x trypsin (Thermo Fisher Scientific, Gibco ${ }^{\mathrm{TM}}$, catalog number: 15250061)

16. Foetal calf serum (FCS) (heat inactivated) (Thermo Fisher Scientific, Gibco ${ }^{\mathrm{TM}}$, catalog number: 10270106)

17. Trypan blue (Thermo Fisher Scientific, Gibco ${ }^{\mathrm{TM}}$, catalog number: 15250061)

18. MitoTracker Deep Red FM probe (APC) (Thermo Fisher Scientific, Molecular Probes ${ }^{\mathrm{TM}}$, catalog number: M22426)

19. Dimethyl sulfoxide (DMSO) (Sigma-Aldrich, catalog number: D8418)

20. Complete $\alpha$-MEM (see Recipes)

21. Mitochondrial staining solution (1\% FBS a-MEM $1 \%$ Mाто) (see Recipes)

22. Cytochalasin $B$ solution (1\%FBS $\alpha-M_{E M}{ }_{1 \% \mathrm{CYTO}}$ ) (see Recipes)

C. Confocal microscopy

1. $0.45 \mu \mathrm{m}$ filter membrane (SARSTEDT, catalog number: 83.1826.001)

2. Pechiney PM999 Parafilm (Bemis, catalog number: PM999)

3. Paper towel

4. Microscope slide

5. Coverslip 
6. Phosphate buffered saline (PBS) (Thermo Fisher Scientific, Gibco ${ }^{T M}$, catalog number: 10010023)

7. Paraformaldehyde (PFA) (Sigma-Aldrich, catalog number: 158127)

8. $1 \mathrm{~N} \mathrm{NaOH}$ (Sigma-Aldrich, catalog number: S2770)

9. $1 \mathrm{~N} \mathrm{HCl}$ (Sigma-Aldrich, catalog number: H9892)

10. Normal goat serum (NGS) (Thermo Fisher Scientific, Invitrogen, catalog number: 31872)

11. Mouse anti-human CD45 primary antibody (Abcam, catalog number: ab8216)

12. Mouse IgG1 isotype (Abcam, catalog number: ab81032)

13. Goat anti-rabbit Alexafluor 405 secondary antibody (Abcam, catalog number: ab175655)

14. Brightmount/Plus aqueous mounting medium (Abcam, catalog number: ab103748)

15. Nail varnish

16. $1 \%$ FBS PBS (see Recipes)

17. $4 \%$ paraformaldehyde (PFA) (see Recipes)

18. Strong and weak block for immunofluorescent staining (see Recipes)

D. Flow cytometry

1. Cell scrapers (Fisher Scientific, catalog number: 08-100-241)

2. Sarstedt $5 \mathrm{ml}$ polystyrene round bottomed flow tubes (SARSTEDT, catalog number: 55.1578 )

3. Phosphate buffered saline (PBS) (Thermo Fisher Scientific, Gibco ${ }^{T M}$, catalog number: 10010023)

4. Human FcR binding inhibitor (Thermo Fisher Scientific, eBioscience ${ }^{\mathrm{TM}}$, catalog number: 14-9161-73)

5. Anti-human CD45 (PE) antibody (Thermo Fisher Scientific, eBioscience ${ }^{\mathrm{TM}}$, catalog number: 12-9459-41)

6. Isotype control (IgG1 kappa) (Thermo Fisher Scientific, eBioscience ${ }^{\mathrm{TM}}$, catalog number: 12-4714)

7. Zombie Aqua Fixable Dye (BioLegend, catalog number: 423101)

E. Bacterial culture and phagocytosis assay

1. Escherichia coli $\mathrm{K} 1$ type strain

2. Phosphate buffered saline (PBS) (Thermo Fisher Scientific, Gibco ${ }^{\mathrm{TM}}$, catalog number: 10010023)

3. LB broth (Lennox) (Sigma-Aldrich, catalog number: L3022)

4. LB broth with agar (Lennox) (Sigma-Aldrich, catalog number: L2897)

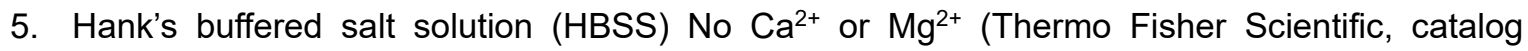
number: 14170138)

6. Complete RPMI 1640 (Thermo Fisher Scientific, Gibco ${ }^{T M}$, catalog number: 21875034)

7. Saponin (Sigma-Aldrich, catalog number: 47036)

8. Gentamycin (Sigma-Aldrich, catalog number: G1397) 
9. Complete $1 \%$ FBS RPMI (see Recipes)

10. $0.5 \%$ saponin (see Recipes)

\section{Equipment}

1. Water bath $\left(37^{\circ} \mathrm{C}\right)$ (Grant Instruments, model: JBN12)

2. Centrifuge (Eppendorf, model: $5810 \mathrm{R}$ )

3. Laminar flow cabinet (Contained Air Solutions, model: BioMAT 2 safety cabinet class 2 )

4. Haemocytometer and cover slips (Hawksley Medical and Laboratory Equipment, model: AC1000 Improved Neubauer, catalog number: BS 748)

5. Incubator (Panasonic Biomedical, model: MCO-170AIC-PE)

6. Dmi1 microscope (Leica Microsystems, model: DMi1)

7. TCS SP5 II Leica confocal microscope (Leica Microsystems, model: TCS SP5 II)

8. BD FACSCanto II Flow cytometer (BD, model: BD FACSCanto II)

9. Vortex (Cole-Palmer Instrument, catalog number: UY-86579-20)

10. 2-20 $\mu$ l pipette (Gilson, catalog number: F123600)

11. 20-200 $\mu$ pipette (Gilson, catalog number: F144565 )

12. 100-1,000 $\mu$ l pipette (Gilson, catalog number: F144566)

13. Midi Plus ${ }^{\mathrm{TM}}$ pipette controller Automatic (Sartorius, catalog number: 710931 )

\section{Software}

1. FlowJo software (FlowJo)

2. Prism 5 software (GraphPad Software)

3. LAS-AF software (Leica confocal microscopy)

4. FACS DIVA software (flow cytometry)

\section{Procedure}

A. Extraction of mononuclear cells from donor Buffy Coats

1. Single donor leukocyte buffy coats are obtained from the Blood Transfusion Centre in Belfast (NIBTS) or from volunteers following ethical approval (approx. $50 \mathrm{ml} / \mathrm{blood}$ bag/volunteer).

2. Pre-warm all media (HBSS, $1 \%$ FBS RPMI and $10 \%$ FBS RPMI) in a water bath $1-2 \mathrm{~h}$ prior to isolation and pre-warm the centrifuge to $20^{\circ} \mathrm{C}$ prior to isolation.

3. Under a laminar flow cabinet decant the donor blood into a T75 flask and dilute (1:2) using sterile HBSS and mix by inversion.

4. Pipette $15 \mathrm{ml}$ of Ficoll-Paque into $4 \times 50 \mathrm{ml}$ Falcons.

5. Very gently layer the diluted blood at a $45^{\circ}$ angle onto the Ficoll, taking care not to mix the layers. Top up the remaining tube with HBSS to make a final volume of $50 \mathrm{ml}$. 
6. Centrifuge all tubes at $480 \times \mathrm{g}, 20^{\circ} \mathrm{C}$ for 20 min without brake.

7. After the spin, locate the pearlescent white layer (buffy layer, shown as lymphocytes, monocytes and platelets layer in Figure 1), which is sedimented through the plasma-density gradient interface. Extract into a new sterile $50 \mathrm{ml}$ Falcon using a Pasteur pipette.

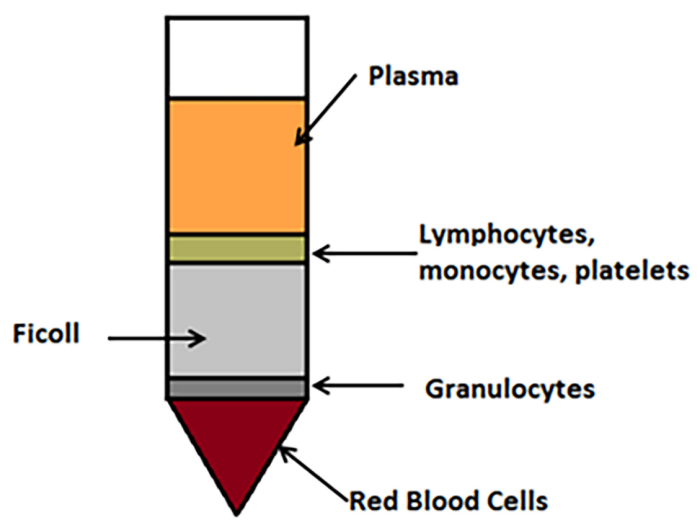

Figure 1. Schematic diagram to illustrate monocyte isolation from peripheral blood. After blood has been layered onto the Ficoll and centrifuged as described above without brake, blood components are separated into layers. A Pasteur pipette is used to carefully remove the lymphocyte, monocyte and platelet layer to use in downstream processing.

8. To wash the cells, add $40 \mathrm{ml}$ of HBSS to the mononuclear cells and mix by inversion.

9. Centrifuge again at $290 \times \mathrm{g}, 4^{\circ} \mathrm{C}$ for $5 \mathrm{~min}$ with brake. Aspirate off supernatant slowly (take care as the pellet may become loose and add another $40 \mathrm{ml} \mathrm{HBSS}$ ). Repeat this wash step 3 times.

10. After the last wash, resuspend the pellet in $10 \mathrm{ml}$ of complete $1 \% \mathrm{FBS}$ RPMI and mix thoroughly by either vortexing or inversion.

11. Place a cover slip on a haemocytometer and load $10 \mu$ of the cell mixture via capillary action through the loading channel.

12. Incubate in the $37^{\circ} \mathrm{C}, 5 \% \mathrm{CO}_{2}$ incubator for at least $5 \mathrm{~min}$ (see Note 1).

13. After this time, view the cells under a microscope at $20 x$ magnification. Count all mononuclear cells (see Note 1).

14. Cells are then seeded at density of $1 \times 10^{6}$ cells/well of a 6 well plate using $3 \mathrm{ml}$ complete $1 \%$ FBS RPMI (see Table 1 for other seeding densities). Incubate at $37^{\circ} \mathrm{C}, 5 \% \mathrm{CO}_{2}$ for at least $2 \mathrm{~h}$ to ensure mononuclear cells have adhered to the plastic of the well. 
Table 1. MSC and MDM (1:20 ratio) seeding densities

\begin{tabular}{|l|l|l|l|l|}
\hline $\begin{array}{l}\text { No. of } \\
\text { MSC/well }\end{array}$ & $\begin{array}{l}\text { No. of } \\
\text { MDM/well }\end{array}$ & Type of plate & $\begin{array}{l}\text { Final volume } \\
(\mathbf{m l}) \text { of } 1 \% \text { FBS } \\
\text { RPMI }\end{array}$ & $\begin{array}{l}\text { Experiment analysis } \\
\text { technique }\end{array}$ \\
\hline $5 \times 10^{4}$ & $1 \times 10^{6}$ & 6 well & 3 & Flow cytometry/Western \\
\hline $1.5 \times 10^{4}$ & $3 \times 10^{5}$ & 24 well & 1 & $\begin{array}{l}\text { ELISA/bioplex/phagocytosi } \\
\text { s assays }\end{array}$ \\
\hline $2.5 \times 10^{3}$ & $5 \times 10^{4}$ & 8 well chamber slide & 0.2 & Confocal microscopy \\
\hline
\end{tabular}

15. After this time non-adherent cells (lymphocytes) are washed off twice with HBSS (by adding 1 $\mathrm{ml} \mathrm{HBSS}$, slight agitation and then aspiration of waste).

16. To promote monocyte-derived macrophage (MDM) maturation, replace complete $1 \%$ FBS RPMI with $3 \mathrm{ml}$ complete RPMI $\mathrm{GM}_{\mathrm{CSF}}$ (see Recipes).

17. Leave cells to rest for $5-7$ days at $37^{\circ} \mathrm{C}, 5 \% \mathrm{CO}_{2}$.

18. After 5-7 days, wash cells twice with HBSS and replace with $3 \mathrm{ml}$ complete $1 \%$ FBS RPMI. Leave cells to rest for $1 \mathrm{~h}$ prior to stimulation experiments.

B. Human mesenchymal stromal cell culture

1. MSC expansion and storage

a. MSC are shipped from Texas, US in liquid nitrogen in $1 \mathrm{ml}$ cyovials at passage number 1 or 2 (P1-P2) meaning they have undergone at least one or two stages of cell splitting in culture. For experimental use (see section Preparing P3 MSC for Experimental Use) cells are only used from P3-P5.

b. Shortly after arrival, defrost 1 vial and culture in pre-warmed $15 \mathrm{ml}$ complete $16 \%$ FBS a-MEM in a T175 flask for less than $24 \mathrm{~h}$.

c. Retain the passage number by splitting cells less than $24 \mathrm{~h}$ later and expanding them using a density of 21,000 cells per flask. A P2 vial can undergo an additional expansion to be stored at P3. Store cells (1 million cells/vial) at either P2 or P3 in liquid nitrogen storage.

2. Preparing $\mathrm{P} 3 \mathrm{MSC}$ for experimental use

Once ready to use, defrost $1 \times \mathrm{P} 3$ cryovial of MSC in the water bath $\left(37^{\circ} \mathrm{C}\right)$ and place entire 1 $\mathrm{ml}$ into $15-20 \mathrm{ml}$ of complete $16 \%$ FBS a-MEM, making sure to feed every other day. Cells are maintained in culture until P5-P6.

C. Direct co-culture of Human Mesenchymal Stromal Cells (MSC and Monocyte-derived Macrophages (MDM)

1. Pre-warm DPBS, HBSS, complete $10 \%$ FBS RPMI, $1 \%$ FBS RPMI, $16.5 \%$ FBS a-MEM and $1 \%$ FBS $\alpha-M E M$ in the water bath at $37^{\circ} \mathrm{C}$ for at least half an hour before the start of the experiment.

Following work has to be completed in a biosafety cabinet with cabinet light switched off. 
2. At $70-80 \%$ confluency, to pre-stain MSC mitochondria, aspirate older $16 \%$ FBS a-MEM from the T175 flask and add $20 \mathrm{ml}$ of staining solution (1\% FBS $\alpha$-MEM міто [see Recipes and Note 2]), incubate for approximately $30 \mathrm{~min}$ at $37^{\circ} \mathrm{C}, 5 \% \mathrm{CO}_{2}$.

3. For MSC being pre-treated with cytochalasin B, $20 \mathrm{ml}$ of $1 \%$ FBS $\alpha$-MEMcrTo is added to cells for 1-2 $\mathrm{h}$ at least prior to staining solution (1\% FBS $\alpha$-MEMмІто). As Cyto $B$ is soluble in DMSO, make sure to have a control flask of cells for DMSO vehicle control.

4. Aspirate $1 \%$ FBS a-MEMcrto from the flask and replace with $1 \%$ FBS a-MEM MIтo, and incubate for $30 \mathrm{~min}$ at $37^{\circ} \mathrm{C}, 5 \% \mathrm{CO}_{2}$.

5. After this time, the staining solution is aspirated from MSC and the cells are washed at least three times in $5 \mathrm{ml}$ DPBS.

6. Aspirate waste DPBS and add $7 \mathrm{ml} 1 \mathrm{x}$ trypsin (diluted in DPBS) and leave in the incubator for approximately 2-5 min.

7. Once the cells are suitably detached, add $7 \mathrm{ml}$ of complete $\alpha$-MEM to counteract trypsin action and pipette the cells into a $50 \mathrm{ml}$ Falcon.

8. Centrifuge the cells at $290 \times g$ for 5 min.

9. During this time, prepare the MDMs by aspirating older culture medium and washing twice with 1-2 $\mathrm{ml}$ of HBSS.

10. Aspirate the remaining HBSS and leave the MDMs to rest in the incubator in $200 \mu \mathrm{l}$ (chamber slide), $1 \mathrm{ml}$ ( 24 well plate) or $3 \mathrm{ml}$ ( 6 well plate) of $1 \%$ FBS RPMI.

11. After MSC centrifugation, aspirate the supernatant and resuspend the pellet in $1 \mathrm{ml} 1 \%$ FBS RPMI (see Note 3).

12. Count cells using a haemocytometer, using trypan blue exclusion and depending on well size needed for experiment, seed corresponding cell densities and co-culture with MDMs for $24 \mathrm{~h}$ (see Table 1).

13. Proceed to either confocal microscopy or flow cytometry procedures.

D. Confocal microscopy staining procedure

1. After co-culture on a chamber slide, carefully aspirate off culture medium, and wash cells twice using $200 \mu \mathrm{l}$ of ice cold PBS.

2. Aspirate the PBS and fix the cells using $100 \mu$ of $4 \%$ PFA solution.

3. Incubate at room temperature with gentle agitation for approximately $15 \mathrm{~min}$.

4. After washing twice again with PBS, proceed to blocking the cells with $100 \mu \mathrm{l}$ strong block for at least $1 \mathrm{~h}$

5. Wash twice with PBS and add $50 \mu \mathrm{l}$ of primary antibody mouse anti-human CD45 primary antibody or isotype control Mouse IgG1 (diluted 1:200) in weak block. Seal slide with Parafilm and incubate slide at $4{ }^{\circ} \mathrm{C}$ overnight with agitation.

6. The next day, repeat the PBS wash step as before and then add $50 \mu \mathrm{l}$ of secondary antibody goat anti-rabbit Alexafluor 405 secondary antibody (diluted 1:1,000 in weak block) for one hour. Incubate in the dark at room temperature for one hour. 
7. Immediately after, repeat the PBS wash step, taking care not to expose slide to light for longer than $10 \mathrm{~min}$.

8. Gently tap the chamber slide onto a paper towel to remove any excess PBS wash and then carefully dislodge the plastic chamber portion to separate the underlying microscope slide.

9. Add approximately 2-3 drops of mounting medium and place a coverslip over the area of stained cells ensuring all air bubbles are removed. Allow to air dry for 30-45 min in the dark.

10. When dry, use commercial nail varnish around the edges to act as glue and fix the coverslip in place.

11. Leave nail varnish to dry in the dark at room temperature. The slide may also be stored at $4{ }^{\circ} \mathrm{C}$ long-term sealed with Parafilm in the dark for future analysis.

12. Proceed to viewing using a confocal microscope (Figure 2).

A

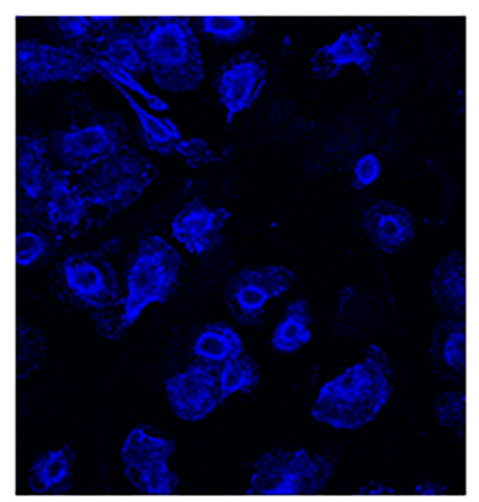

CD45
B

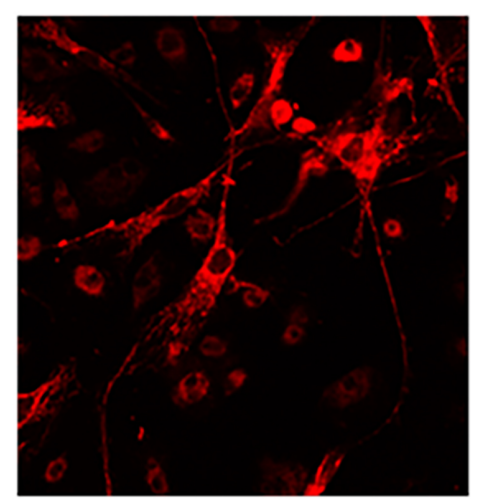

MitoRed
C

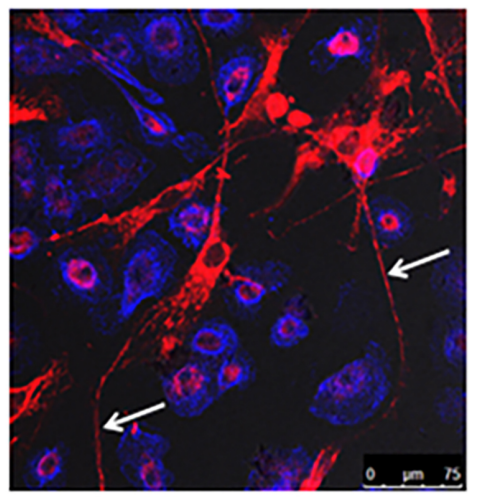

Merged

Figure 2. Visualization of transfer of MSC mitochondria to MDM by confocal microscopy.

A. MDM express surface CD45 marker (blue); B. MSC mitochondria are stained with MitoTracker probe (red); C. After $24 \mathrm{~h}$ of co-culture mitochondrial positive TNT are observed, protruding from the MSC (arrows) ranging up to $200 \mu \mathrm{m}$ in length. Mitochondrial transfer from MSC to MDM is evidenced by co-localisation of blue and red staining (pink). (Images were taken at magnification $10 \times 63$, scale bar $=75 \mu \mathrm{m}$ ). (Adapted from Jackson et al., $\underline{\text { Stem Cells. }}$ 2016 Aug; 34(8): 2210-23)

\section{E. Flow cytometry staining procedure}

1. Immediately after co-culture place the 6 well plate on ice and aspirate off culture medium.

2. Add $1 \mathrm{ml}$ of ice cold $1 \%$ FBS PBS to the cell co-culture and lightly scrape using a cell scraper all over the well, so as to gently detach cells from the plastic surface.

3. Once detached, place the cells into $5 \mathrm{ml}$ polystyrene round bottomed flow tubes and centrifuge the cells at $800 \times g$ for $5 \mathrm{~min}$.

4. In order to test viability of the cells after culture and detachment, it is necessary to include a live/dead control. This requires a separate tube of unstained cells and the addition of a live/dead marker stain Zombie Aqua (use according to manufacturer's protocol). 
5. Decant off the supernatant, leaving the pellet submerged in approximately $100 \mu \mathrm{l}$ of $1 \%$ FBS PBS.

6. Vortex vigorously and add $2.5 \mu \mathrm{g} / 1 \times 10^{6}$ cells of FcR binding inhibitor to the cells and vortex this again.

7. Leave in the dark and on ice for $30 \mathrm{~min}$.

8. After this time directly add $5 \mu \mathrm{l} / 1 \times 10^{6}$ cells of anti-human CD45 (PE) or Isotype control (IgG1 kappa) to the cell suspension and vortex again to mix thoroughly.

9. Leave in the dark and on ice for $20 \mathrm{~min}$.

10. Following this, add an additional $1 \mathrm{ml}$ of $1 \%$ FBS PBS to wash the cells and dispose of any unbound antibody. Vortex thoroughly.

11. Centrifuge the suspension as before at $800 \times g$ for $5 \mathrm{~min}$.

12. Decant the supernatant and repeat this wash step a final time. Resuspend the pellet in $200 \mu \mathrm{l}$ of $1 \%$ FBS PBS and place the cells on ice in preparation for flow cytometry.

13. Use FACS DIVA software to perform analysis. To rule out MSC-macrophage aggregates, single cells were gated as W-FSC vs. A-FSC and from this we defined CD45-PE+MitoRed-APCpopulation as MDM and also MitoRed-APC+CD45-PE- population as MSC (Figure 3). 

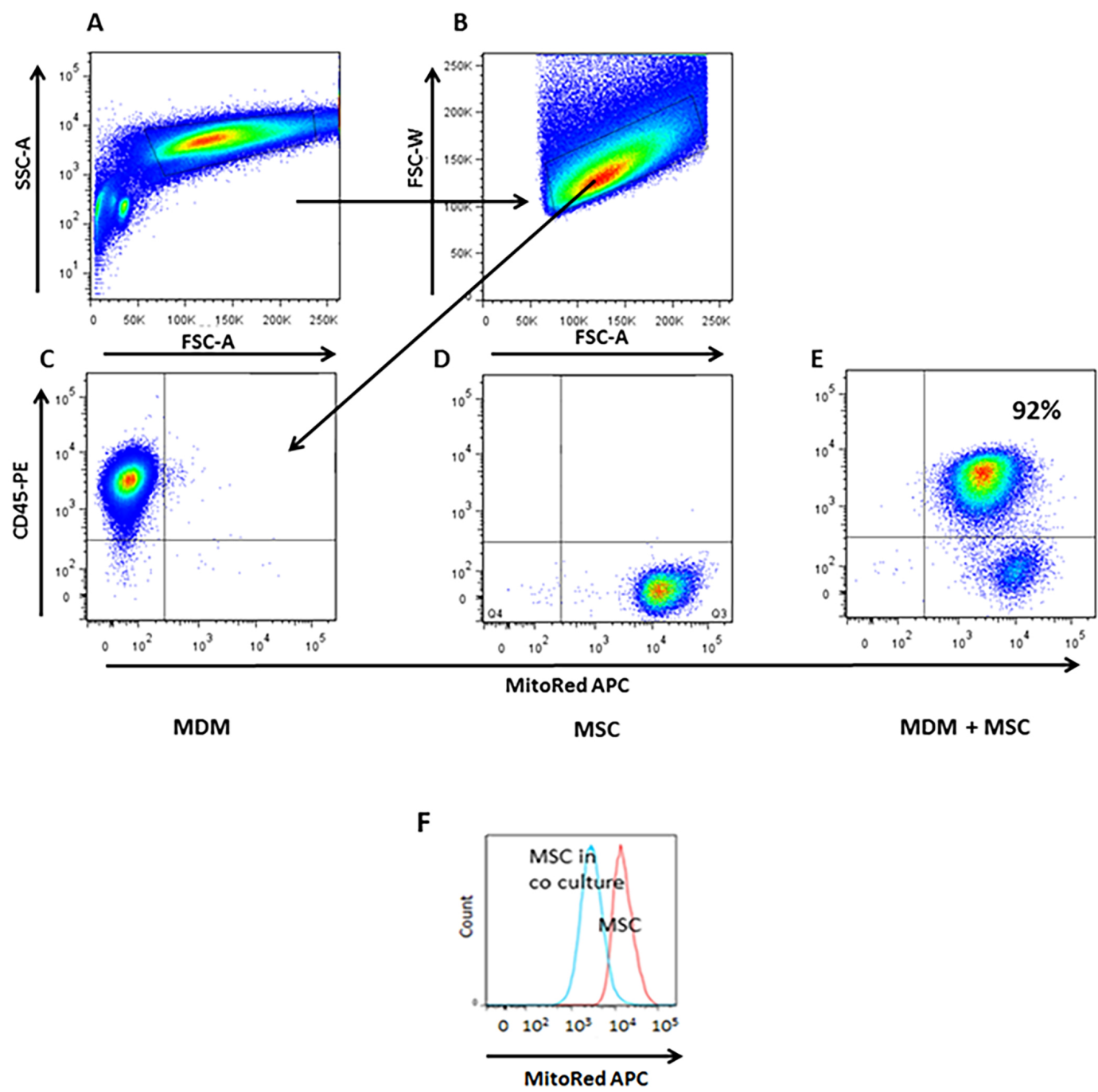

Figure 3. Quantification of mitochondrial transfer from MSC to MDM by flow cytometry. A-B. Live single cells were gated as W-FSC vs. A-FSC and from this we defined C. C. CD45-PE ${ }^{+}$MDM population without co-culture with MSC is MitoRed-APC negative. D. APC ${ }^{+}$ MSC poplulation alone is positive for mitochondria but negative for macrophage marker, CD45-PE- E. After $4 \mathrm{~h}$ in co-culture MDM had acquired $92 \%$ of MSC mitochondria shown by the MitoRed fluorescence marker APC. F. Histogram ilustrates a reduction in MitoRed fluorescence in the MSC population indicating robust donation of mitochondria to the MDM population. (Adapted from Jackson et al., Stem Cells. 2016 Aug; 34(8): 2210-23)

F. Bacterial culture and phagocytosis assay

1. Inoculate $15 \mathrm{ml}$ of LB broth with a stored aliquot of E.coli $\mathrm{K} 1$ type strain (sterile LB broth/15\% glycerol) and incubate at $37^{\circ} \mathrm{C}$ to grow an overnight culture.

2. Use a 24-well plate to set up a direct co-culture with MDM and MSC (see Table 1 for seeding densities).

3. For E. coli, a total viable count of $1 \times 10^{8}$ colony forming units (CFU/ml) equates to an optical density (OD) of approximately $0.25-0.3$ at $600 \mathrm{~nm}$. 
4. Spin bacteria at $15,000 \times \mathrm{g}$, for $5 \mathrm{~min}$ and resuspend the pellet using sterile $1 \mathrm{ml} \mathrm{HBSS}$.

5. After $24 \mathrm{~h}$ of MDM and MSC co-culture infect cells using a Multiplicity of Infection of 10 (MOI 10, see Note 4 for $\mathrm{MOI}$ calculation), using HBSS as a vehicle control.

6. Incubate for $4 \mathrm{~h}$ at $37^{\circ} \mathrm{C}, 5 \% \mathrm{CO}_{2}$.

7. After this time, retrieve the supernatant from the cells for quantification of extracellular bacteria and make a dilution series of $10^{-1}$ to $10^{-6}$ in sterile PBS.

8. Pipette $3 \times 20 \mu \mathrm{l}$ spots of each dilution out onto LB agar and incubate overnight at $37^{\circ} \mathrm{C}$.

9. For intracellular bacteria wash the cells in $1 \mathrm{ml}$ sterile PBS 3 times, aspirate wash and then add $300 \mu \mathrm{g} / \mathrm{ml}$ of gentamycin (diluted in $1 \%$ FBS RPMI), $100 \mu \mathrm{l} /$ well and incubate at $37^{\circ} \mathrm{C}$ for $1 \mathrm{~h}$ to kill adherent bacteria.

10. After this time wash the cells in $1 \mathrm{ml}$ sterile PBS 3 times, aspirate wash and add $100 \mu \mathrm{l}$ of $0.5 \%$ saponin to lyse the cells and leave the bacteria intact.

11. After $5 \mathrm{~min}$, add an additional $900 \mu \mathrm{l}$ of sterile PBS to each well to dilute saponin, and repeat the dilution series again, plating out each dilution. Incubate plates at $37^{\circ} \mathrm{C}$.

12. Count CFU/ml within $24 \mathrm{~h}$ (Figures $4 \mathrm{D}-4 \mathrm{G}$ ). 
A

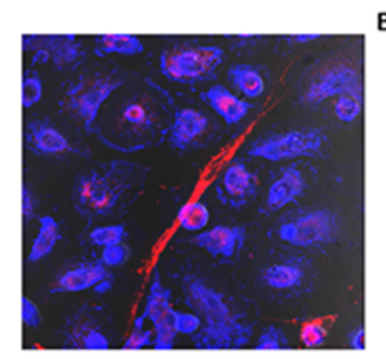

MSC + DMSO

C
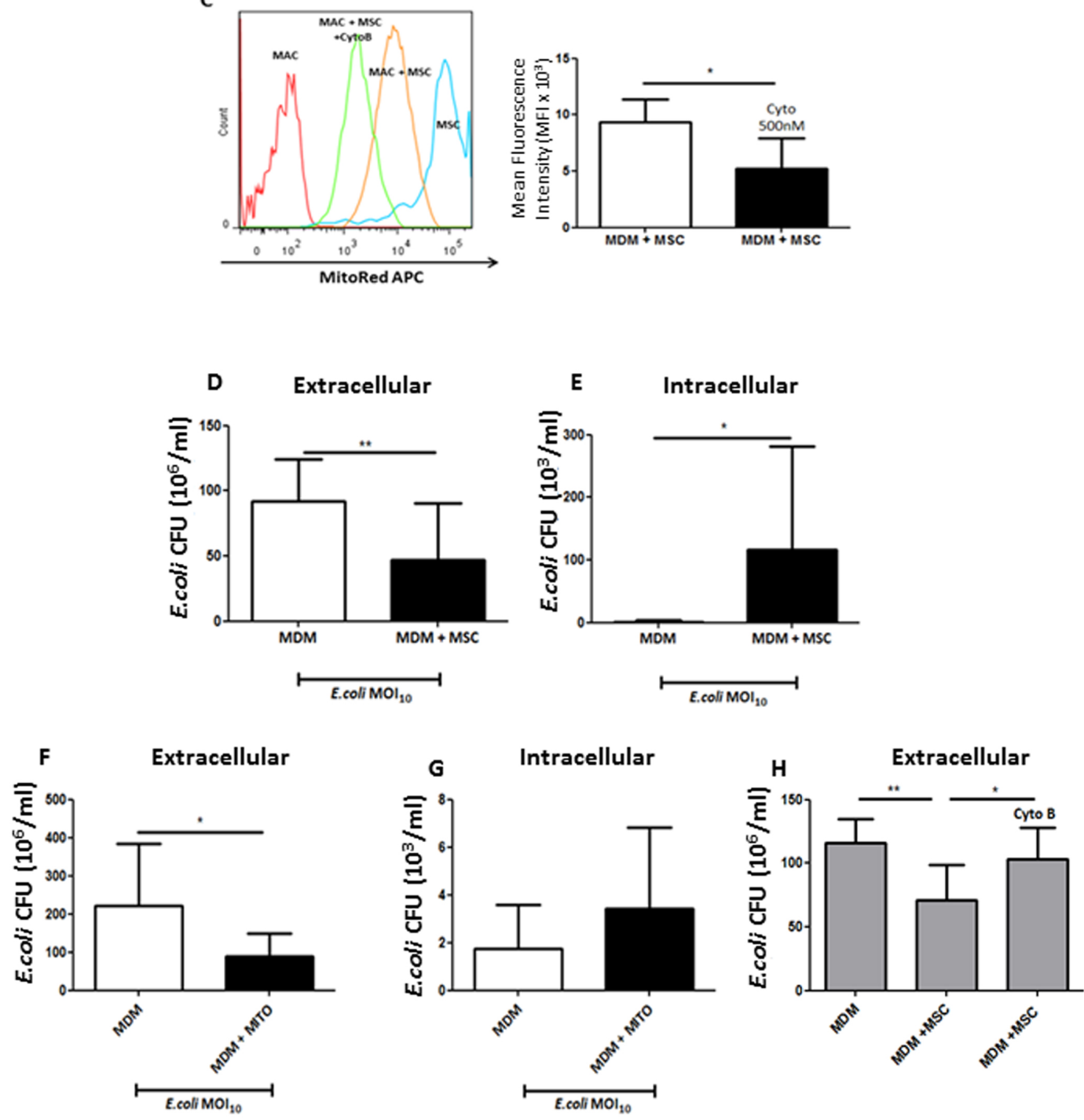

Figure 4. Cytochalasin B blocks TNT-mediated mitochondrial transfer thereby preventing MSC functional effects on MDM. A. Confocal microscopy shows distinctive spindle MSC shape (red) with MDM (blue) in co-culture. TNT is shown to be present with robust mitochondrial transfer to MDM. B. Cytochalasin B pre-treatment of MSC inhibited actin filament elongation, causing them to appear rounded with loss of TNT structures. Mitochondrial transfer is still however evident due to probable microvesicle secretion from MSC to MDM (magnification $10 \times 63$, scale bar $=50 \mu \mathrm{m}$ ). C. Cytochalasin B treatment of MSC showed that MitoRed mean fluorescence intensity (MFI) decreased by $50 \%$ in MDMs in co-culture $\left({ }^{*} P<\right.$ 
0.05 Mann Whitney $U$ test). D. After $4 \mathrm{~h}$ of live E.coli infection of the co-culture untreated MSC significantly reduced extracellular CFU, whilst simultaneously elevated intracellular CFU in macrophages, an effect recapitulated by stimulation with isolated $M S C$ mitochondria $(F+G) . H$. This effect was completely abrogated with cytochalasin B-treated MSC as even in their presence MDM phagocytosis remained unaffected. (Adapted from Jackson et al., Stem Cells. 2016 Aug; 34(8): 2210-23)

\section{Data analysis}

In vitro experiments using 96-well and 24-well plates were performed in triplicate, of which means \pm SD were calculated for at least 3 independent experiments. For flow cytometry median fluorescence intensity was calculated using FlowJo software version 7. Data were tested for normality by plotting histograms of frequency distribution and using the D'Agostino and Pearson Omnibus normality test in GraphPad Prism 5. Comparisons of parametric data were analysed by Student's $t$-test, one-way or two-way ANOVA for multiple groups. Post hoc analysis using the Bonferroni method was then used to test where significance lay. For non-parametric data the Mann Whitney $U$ and Kruskal Wallis test were used with the Dunn's method as a post test. Statistical significance was considered when $P<0.05$ and all data are displayed as mean \pm SD. All Statistical analysis was performed using GraphPad Prism version 5. All of the above statistical information and supporting documentation can be found in Jackson et al, Stem Cells. 2016 Aug; 34(8):2210-23 with URL: http://onlinelibrary.wiley.com/doi/10.1002/stem.2372/full.

\section{$\underline{\text { Notes }}$}

1. The 5 min incubation step allows mononuclear cells to adhere to the haemocytometer and are easily distinguished next to lymphocytes. Monocytes appear 'blurry', 'splodgy' or 'ghost-like' whereas lymphocytes appear much clearer and sharper. In the case where the original suspension is too dense with cells, a $1: 10$ or 1:20 dilution is required to properly visualise mononuclear cells.

2. As the MitoTracker probe is supplied in a reduced form, it may be susceptible to oxidases in serum, and therefore the staining solution consists of up to 1\% FCS content to allow for maximum staining potential (https://www.thermofisher.com/order/catalog/product/M22426)

3. All stimulation experiments with co-culture of MSC and MDMs are performed in $1 \%$ FBS RPMI media.

4. Calculation of multiplicity of infection $\mathrm{MOI}$

For $E$. coli $\mathrm{K} 1$, an optical density of $0.25-0.3$ at $600 \mathrm{~nm}$ equates to approximately $1 \times 10^{8}$ $\mathrm{CFU} / \mathrm{ml}$ of bacteria. This varies for each strain of E.coli and indeed for different types of bacteria. Therefore beginning bacterial work, a growth curve (CFU/ml vs. time) and also absorbance (OD) vs. $\mathrm{CFU} / \mathrm{ml}$ must be performed to accurately estimate bacterial rates of 
growth and also how OD varies with bacterial concentration. Once this is established, $\mathrm{MOI}$ can then be estimated. This is the number of bacterial cells added per MDM in each infection. See example below.

Initial MDM seeding density $=3 \times 10^{5}$ cells ( 24 well plate)

Starting $\mathrm{OD}_{600 \mathrm{~nm}}(0.25-0.3)=1 \times 10^{8} \mathrm{CFU} / \mathrm{ml}$ of $E$. coli

Therefore MOI $1=1 \times 10^{5} \mathrm{CFU} / \mathrm{ml}$ of $E$. coli ( 1 bacterial cell: $1 \mathrm{MDM}$ cell)

MOI $10=1 \times 10^{6} \mathrm{CFU} / \mathrm{ml}$ of $E$. coli $(10: 1)$

MOI $100=1 \times 10^{7} \mathrm{CFU} / \mathrm{ml}$ of $E$. coli $(100: 1)$

\section{Recipes}

1. Complete $1 \%$ FBS RPMI

$500 \mathrm{ml}$ RPMI 1640

$5 \mathrm{ml}$ of FCS $(1 \%)$ or $50 \mathrm{ml} \mathrm{FCS}(10 \%)$

$5 \mathrm{ml}$ Pen-Strep (1\%)

2. Complete RPMI ${ }_{\mathrm{GM}-\mathrm{CSF}}$

500 ml RPMI 1640

$50 \mathrm{ml} \mathrm{FCS} \mathrm{(10 \% )}$

$5 \mathrm{ml}$ Pen-Strep (1\%)

$10 \mathrm{ng} / \mathrm{ml}$ GM-CSF

3. Complete $\alpha-M E M$

$500 \mathrm{ml} \mathrm{a}-\mathrm{MEM}$

$5 \mathrm{ml}$ of FCS (1\%) or $80 \mathrm{ml} \mathrm{FCS} \mathrm{(16.5 \% )}$

$5 \mathrm{ml}$ Pen-Strep (1\%)

$5 \mathrm{ml}$ L-glutamine (1\%)

4. Mitochondrial staining solution (1\% FBS a-MEM Мाто)

$500 \mathrm{ml} \mathrm{a}-M E M$

$5 \mathrm{ml}$ of FCS $(1 \%)$

$5 \mathrm{ml}$ Pen-Strep (1\%)

$5 \mathrm{ml} \mathrm{L-glutamine} \mathrm{(1 \% )}$

200 nM MitoTracker Deep Red FM probe

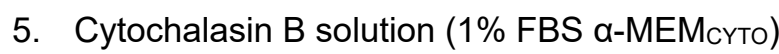

$500 \mathrm{ml} \mathrm{a}-\mathrm{MEM}$

$5 \mathrm{ml}$ of FCS $(1 \%)$

$5 \mathrm{ml}$ Pen-Strep (1\%)

$5 \mathrm{ml}$ L-glutamine (1\%)

$500 \mathrm{nM}$ cytochalasin B or same volume for DMSO (vehicle control)

6. $1 \%$ FBS PBS

$50 \mathrm{ml}$ sterile PBS 
$0.5 \mathrm{ml}$ of FCS (1\%)

7. $4 \%$ paraformaldehyde (PFA)

a. Add $4 \mathrm{~g}$ of paraformaldehyde to $50 \mathrm{ml}$ of double distilled $\mathrm{H}_{2} \mathrm{O}\left(\mathrm{ddH}_{2} \mathrm{O}\right)$

b. Add $1 \mathrm{ml} 1 \mathrm{~N} \mathrm{NaOH}$ to the solution and heat on the heating block at $60^{\circ} \mathrm{C}$ until PFA is dissolved

c. Add $10 \mathrm{ml}$ of $10 x$ PBS to the mixture and allow to cool to room temperature

d. The $\mathrm{pH}$ is then adjusted to 7.4 with $1 \mathrm{~N} \mathrm{HCl}$

e. Adjust the final volume of the mixture to $100 \mathrm{ml}$ using $\mathrm{ddH}_{2} \mathrm{O}$

f. Use a $0.45 \mu \mathrm{M}$ membrane to filter the solution and remove debris. Aliquots may be stored up to 3-6 months at $-20^{\circ} \mathrm{C}$

8. Strong and weak block for immunofluorescent staining

Strong block: $45 \mathrm{ml}$ PBS $+5 \mathrm{ml}$ of NGS (10\%)

Weak block: $49 \mathrm{ml}$ PBS $+1 \mathrm{ml}$ of NGS $(2 \%)$

9. $0.5 \%$ saponin

$50 \mathrm{mg}$ of saponin powder

$10 \mathrm{ml}$ sterile PBS

\section{Acknowledgments}

This work was funded by Medical Research Council of the UK MR/L017229/1 (ADK), NHLBI HL51854 (MAM). Some of the materials employed in this work were provided by the Texas A\&M Health Science Center College of Medicine Institute for Regenerative Medicine at Scott \& White through a grant from NCRR of the NIH, Grant \# P4ORR017447. This protocol was adapted from our publication (Jackson et al., 2016).

\section{$\underline{\text { References }}$}

1. Ahmad, T., Mukherjee, S., Pattnaik, B., Kumar, M., Singh, S., Kumar, M., Rehman, R., Tiwari, B. K., Jha, K. A., Barhanpurkar, A. P., Wani, M. R., Roy, S. S., Mabalirajan, U., Ghosh, B. and Agrawal, A. (2014). Miro1 regulates intercellular mitochondrial transport \& enhances mesenchymal stem cell rescue efficacy. EMBO J 33(9): 994-1010.

2. de Almeida, M. C., Silva, A. C., Barral, A. and Barral Netto, M. (2000). A simple method for human peripheral blood monocyte isolation. Mem Inst Oswaldo Cruz 95(2): 221-223.

3. Dominici, M., Le Blanc, K., Mueller, I., Slaper-Cortenbach, I., Marini, F., Krause, D., Deans, R., Keating, A., Prockop, D. and Horwitz, E. (2006). Minimal criteria for defining multipotent mesenchymal stromal cells. The international society for cellular therapy position statement. Cytotherapy 8(4): 315-317.

4. Guilliams, M., De Kleer, I., Henri, S., Post, S., Vanhoutte, L., De Prijck, S., Deswarte, K., Malissen, B., Hammad, H. and Lambrecht, B. N. (2013). Alveolar macrophages develop from 
fetal monocytes that differentiate into long-lived cells in the first week of life via GM-CSF. J Exp Med 210(10): 1977-1992.

5. Gupta, N., Krasnodembskaya, A., Kapetanaki, M., Mouded, M., Tan, X., Serikov, V. and Matthay, M. A. (2012). Mesenchymal stem cells enhance survival and bacterial clearance in murine Escherichia coli pneumonia. Thorax 67(6): 533-539.

6. Gupta, N., Su, X., Popov, B., Lee, J. W., Serikov, V. and Matthay, M. A. (2007). Intrapulmonary delivery of bone marrow-derived mesenchymal stem cells improves survival and attenuates endotoxin-induced acute lung injury in mice. $J$ Immunol 179(3): 1855-1863.

7. Islam, M. N., Das, S. R., Emin, M. T., Wei, M., Sun, L., Westphalen, K., Rowlands, D. J., Quadri, S. K., Bhattacharya, S. and Bhattacharya, J. (2012). Mitochondrial transfer from bone-marrow-derived stromal cells to pulmonary alveoli protects against acute lung injury. Nat Med 18(5): 759-765.

8. Jackson, M. V., Morrison, T. J., Doherty, D. F., McAuley, D. F., Matthay, M. A., Kissenpfennig, A., O'Kane, C. M. and Krasnodembskaya, A. D. (2016). Mitochondrial transfer via tunneling nanotubes is an important mechanism by which mesenchymal stem cells enhance macrophage phagocytosis in the in vitro and in vivo models of ARDS. Stem Cells 34(8): 2210-2223.

9. Krasnodembskaya, A., Samarani, G., Song, Y., Zhuo, H., Su, X., Lee, J. W., Gupta, N., Petrini, M. and Matthay, M. A. (2012). Human mesenchymal stem cells reduce mortality and bacteremia in gram-negative sepsis in mice in part by enhancing the phagocytic activity of blood monocytes. Am J Physiol Lung Cell Mol Physiol 302(10): L1003-1013.

10. Krasnodembskaya, A., Song, Y., Fang, X., Gupta, N., Serikov, V., Lee, J. W. and Matthay, M. A. (2010). Antibacterial effect of human mesenchymal stem cells is mediated in part from secretion of the antimicrobial peptide LL-37. Stem Cells 28(12): 2229-2238.

11. Lee, J. W., Krasnodembskaya, A., McKenna, D. H., Song, Y., Abbott, J. and Matthay, M. A. (2013). Therapeutic effects of human mesenchymal stem cells in exvivo human lungs injured with live bacteria. Am J Respir Crit Care Med 187(7): 751-760.

12. Li, X., Zhang, Y., Yeung, S. C., Liang, Y., Liang, X., Ding, Y., Ip, M. S., Tse, H. F., Mak, J. C. and Lian, Q. (2014). Mitochondrial transfer of induced pluripotent stem cell-derived mesenchymal stem cells to airway epithelial cells attenuates cigarette smoke-induced damage. Am J Respir Cell Mol Biol 51(3): 455-465.

13. Liu, K., Ji, K., Guo, L., Wu, W., Lu, H., Shan, P. and Yan, C. (2014). Mesenchymal stem cells rescue injured endothelial cells in an in vitro ischemia-reperfusion model via tunneling nanotube like structure-mediated mitochondrial transfer. Microvasc Res 92: 10-18.

14. Mei, S. H., Haitsma, J. J., Dos Santos, C. C., Deng, Y., Lai, P. F., Slutsky, A. S., Liles, W. C. and Stewart, D. J. (2010). Mesenchymal stem cells reduce inflammation while enhancing bacterial clearance and improving survival in sepsis. Am J Respir Crit Care Med 182(8): 1047-1057. 
15. Nemeth, K., Leelahavanichkul, A., Yuen, P. S., Mayer, B., Parmelee, A., Doi, K., Robey, P. G., Leelahavanichkul, K., Koller, B. H., Brown, J. M., Hu, X., Jelinek, I., Star, R. A. and Mezey, E. (2009). Bone marrow stromal cells attenuate sepsis via prostaglandin $E(2)$-dependent reprogramming of host macrophages to increase their interleukin-10 production. Nat Med 15(1): 42-49.

16. Ware, L. B. and Matthay, M. A. (2000). The acute respiratory distress syndrome. N Engl J Med 342(18): 1334-1349.

17. Wilson, J. G., Liu, K. D., Zhuo, H., Caballero, L., McMillan, M., Fang, X., Cosgrove, K., Vojnik, R., Calfee, C. S., Lee, J. W., Rogers, A. J., Levitt, J., Wiener-Kronish, J., Bajwa, E. K., Leavitt, A., McKenna, D., Thompson, B. T. and Matthay, M. A. (2015). Mesenchymal stem (stromal) cells for treatment of ARDS: a phase 1 clinical trial. Lancet Respir Med 3(1): 24-32.

18. Xu, J., Qu, J., Cao, L., Sai, Y., Chen, C., He, L. and Yu, L. (2008). Mesenchymal stem cell-based angiopoietin-1 gene therapy for acute lung injury induced by lipopolysaccharide in mice. J Pathol 214(4): 472-481.

19. Xu, J., Woods, C. R., Mora, A. L., Joodi, R., Brigham, K. L., lyer, S. and Rojas, M. (2007). Prevention of endotoxin-induced systemic response by bone marrow-derived mesenchymal stem cells in mice. Am J Physiol Lung Cell Mol Physiol 293(1): L131-141.

20. Zheng, G., Huang, L., Tong, H., Shu, Q., Hu, Y., Ge, M., Deng, K., Zhang, L., Zou, B., Cheng, B. and $\mathrm{Xu}$, J. (2014). Treatment of acute respiratory distress syndrome with allogeneic adipose-derived mesenchymal stem cells: a randomized, placebo-controlled pilot study. Respir Res 15: 39. 